\title{
Danos do complexo broca-podridão à produtividade e à qualidade da cana-de-açúcar fertirrigada com doses de nitrogênio
}

\author{
Luiz Eduardo da Rocha Pannuti(1), Edson Luiz Lopes Baldin(1), \\ Glauber José de Castro Gava ${ }^{(2)}$, Oriel Tiago Kölln ${ }^{(3)}$ e Juliana Cristina Sodário Cruz ${ }^{(2)}$
}

\begin{abstract}
(1)Universidade Estadual Paulista, Faculdade de Ciências Agronômicas, Caixa Postal 237, CEP $18603-970$ Botucatu, SP. E-mail: luizpannutixl@yahoo.com.br, elbaldin@fca.unesp.br ${ }^{(2)}$ Agência Paulista de Tecnologia dos Agronegócios, Polo Centro-Oeste, Rodovia Deputado Leônidas Pacheco Ferreira (Jaú-Bariri), Km 304, Caixa Postal 66, CEP 17201-970 Jaú, SP. E-mail: ggava@apta.sp.gov.br ${ }^{(3)}$ Centro de Ciência e Tecnologia do Bioetanol, Laboratório Nacional de Ciência e Tecnologia do Bioetanol, Rua Giuseppe Maximo Scolfaro, no 10.000, Polo de Alta Tecnologia II, Caixa Postal 6.170, CEP 13083-970 Campinas, SP. E-mail: oriel.kolln@bioetanol.org.br
\end{abstract}

Resumo - O objetivo deste trabalho foi avaliar o efeito da fertirrigação nitrogenada sobre os danos causados pelo complexo broca-podridão à produtividade e à qualidade da cana-de-açúcar. $\mathrm{O}$ experimento foi realizado em campo, em delineamento de blocos ao acaso, com quatro repetições e cinco doses de $\mathrm{N}\left(0,50,100,150\right.$ e $\left.200 \mathrm{~kg} \mathrm{ha}^{-1}\right)$, aplicadas por irrigação por gotejamento. Quantificaram-se as seguintes variáveis: número de orifícios causados por Diatraea saccharalis (Lepidoptera: Crambidae); número de internódios infectados com a podridão-vermelha; percentagem de incidência de podridão-vermelha; produtividade de colmos; e teor de açúcar. Em laboratório, foram avaliados a atratividade e o consumo de fragmentos de colmos por lagartas de quarto instar, em testes com ou sem chance de escolha. A irrigação nitrogenada aumentou a incidência de $D$. saccharalis e de podridão-vermelha. O número de orifícios causados pelas lagartas correlacionou-se à ocorrência de podridão-vermelha. A percentagem de açúcar diminuiu com o aumento do número de internódios danificados pela podridão-vermelha. As doses de $\mathrm{N}$ não afetaram a atratividade dos fragmentos de colmos de cana-de-açúcar; no entanto, maiores doses de $\mathrm{N}$ fertilizante aumentaram o consumo destes fragmentos por lagartas de $D$. saccharalis. Apesar dos danos à qualidade, a adubação nitrogenada aumentou expressivamente a produtividade de colmos e de açúcar.

Termos para indexação: Colletotrichum falcatum, Diatraea saccharalis, Saccharum, atratividade, broca-da-cana-de-açúcar, podridão-vermelha.

\section{Damages caused by the borer-rot complex to the productivity and quality of sugarcane fertigated with nitrogen doses}

\begin{abstract}
The objective of this work was to evaluate the effect of nitrogen-fertigation on the damage caused by the borer-rot complex to the productivity and quality of fertigated sugarcane. The experiment was carried out in field, using a randomized complete block design, with four replicates and five $\mathrm{N}$ doses $(0,50100,150$, and $200 \mathrm{~kg} \mathrm{ha}^{-1}$ ) applied through drip irrigation. The following variables were determined: number of holes caused by Diatraea saccharalis (Lepidoptera: Crambidae); number of internodes infected with red rot; incidence percentage of red rot; stalk productivity; and sugar content. In laboratory, the attractiveness and the consumption of culm fragments by fourth instar caterpillars, in trials with or without choice, were evaluated. Nitrogen fertigation increased the incidence of $D$. saccharalis and red rot. The number of holes produced by the larvae was correlated with the occurrence of red rot. Sugar percentage reduced with the increase in the number of red rot affected internodes. Nitrogen doses did not affect the attractiveness of sugarcane culm fragments; however, higher $\mathrm{N}$ doses increased the consumption of these fragments by D. saccharalis caterpillars. Despite the damages to quality, nitrogen fertilization expressively enhanced the productivity of stalks and sugar.
\end{abstract}

Index terms: Colletotrichum falcatum, Diatraea saccharalis, Saccharum, attractiveness, sugarcane borer, red rot.

\section{Introdução}

O Brasil é o maior produtor mundial de cana-de-açúcar, cultura que se destaca na produção de etanol e de energia renovável (Vale et al., 2011). Apesar do elevado nível tecnológico em uso nas lavouras brasileiras, o fornecimento inadequado de nutrientes
(Vale et al., 2011), o manejo hídrico inadequado (Wiedenfeld \& Enciso, 2008; Oliveira et al., 2011) e o ataque de insetos-praga (Dinardo-Miranda et al., 2008, 2012) podem comprometer a produtividade da cana-de-açúcar (Carvalho et al., 2011), e exigem constante atenção. 
Embora tenha elevado potencial para aumentar a produtividade, $\mathrm{o}$ fracionamento das doses de nutrientes por meio da fertirrigação tem sido pouco adotado nas regiões produtoras de cana-de-açúcar (Andrade Júnior et al., 2012).

$\mathrm{O}$ aumento de produtividade e a expansão do cultivo da cana-de-açúcar pelo território nacional têm sido acompanhados do surgimento de novas pragas e do aumento da incidência de outras já bem conhecidas na cultura, como a broca-da-cana Diatraea saccharalis (Lepidoptera: Crambidae) (Dias et al., 2011). A broca abre galerias no interior dos colmos, e pode reduzir drasticamente a produtividade e favorecer a entrada de microrganismos oportunistas, causadores da podridão-vermelha (Colletotrichum falcatum associado ou não a Fusarium moniliforme). $\mathrm{O}$ ataque da praga diminui o teor de açúcar (pela inversão da sacarose armazenada na planta) e contamina o caldo, o que dificulta a fermentação (Dinardo-Miranda, 2008; Dinardo-Miranda et al., 2011).

Apesar do uso disseminado de $\mathrm{N}$ na cultura e do conhecimento quanto ao benefício do aumento da disponibilidade hídrica sobre a produtividade da cana-de-açúcar, faltam informações quanto aos efeitos da associação da adubação nitrogenada à irrigação sobre a predisposição da cultura a insetos-praga e a doenças. Diversas pesquisas, como as de Taneja \& Dhindwal (1982) e Zing et al. (1982), relataram a relação entre adubação nitrogenada e incidência de insetos-praga, em diversas culturas; porém, para cana-de-açúcar, ainda faltam informações na literatura.

O objetivo deste trabalho foi avaliar o efeito da fertirrigação nitrogenada sobre os danos causados pelo complexo broca-podridão à produtividade e à qualidade da cana-de-açúcar..

\section{Material e Métodos}

O trabalho foi realizado na área experimental da Unidade de Pesquisa e Desenvolvimento de Jaú, da Agência Paulista de Tecnologias do Agronegócio, SP $\left(22^{\circ} 17^{\prime} \mathrm{S}, 48^{\circ} 34^{\prime} \mathrm{W}\right.$, altitude de $\left.580 \mathrm{~m}\right)$, e nos laboratórios da Universidade Estadual Paulista, em Botucatu, SP.

O solo da área foi classificado como Latossolo Vermelho (Santos et al., 2006) de textura argilosa, e a variedade de cana utilizada foi a SP80-3280 (4o e 5o cortes). Esta variedade é considerada suscetível ao ataque da broca-da-cana-de-açúcar (Dinardo-Miranda,
2003). A variedade é altamente produtiva e apresenta exigência média em fertilidade do solo (Faroni et al., 2007).

O experimento foi conduzido com irrigação, em delineamento de blocos ao acaso, com cinco doses de $\mathrm{N}\left(0,50,100,150\right.$ e $\left.200 \mathrm{~kg} \mathrm{ha}^{-1}\right)$, aplicadas em fertirrigação, e quatro repetições. As parcelas foram constituídas de cinco fileiras com $30 \mathrm{~m}$ de comprimento, subdivididas em três subparcelas com $10 \mathrm{~m}$ de comprimento. Duas subparcelas foram utilizadas para as avaliações sequenciais de $D$. saccharalis, e a terceira para a determinação da produtividade.

O plantio em linha dupla foi adotado, com espaçamento de $1,80 \mathrm{~m}$ entre as linhas duplas e sistema de irrigação por gotejamento subterrâneo. O tubo gotejador foi enterrado a $20 \mathrm{~cm}$ de profundidade da superfície do solo, no meio da linha dupla. O tubo gotejador utilizado foi o Dripnet PC 22135 FL, com vazão de $1,0 \mathrm{~L}$ por hora, com gotejadores a cada $0,5 \mathrm{~m}$.

A adubação potássica foi igual para todos os tratamentos (150 kg ha-1 de $\mathrm{K}_{2} \mathrm{O}$, na forma de $\left.\mathrm{KCl}\right)$, aplicada ao longo do desenvolvimento da cultura por meio da fertirrigação. As diferentes doses de $\mathrm{N}$-fertilizante, na forma de ureia, também foram aplicadas por fertirrigação, ao longo do ciclo da cultura.

O controle da lâmina de água aplicada pelo sistema de irrigação, foi feito por meio de tensiometria e de cálculos da evapotranspiração diária da cultura, conforme Penman-Monteith (FAO), tendo-se como objetivo a reposição de $100 \%$ da lâmina evapotranspirada. Foram elaboradas estimativas decendiais de balanço hídrico e calculadas as deficiências hídricas (DEF), nos anos agrícolas de 2009/2010 e de 2010/2011. Na safra de 2009/2010, a precipitação ocorrida foi de $1.435 \mathrm{~mm}$, e a lâmina de água aplicada pela irrigação foi de $390 \mathrm{~mm}$, distribuída ao longo do ciclo de crescimento da cultura $(1.825 \mathrm{~mm}$, no total). As médias de temperaturas máxima e mínima foram de 29,1 e $16,4^{\circ} \mathrm{C}$, respectivamente. Na safra de 2010/2011, a precipitação ocorrida foi de $1.462 \mathrm{~mm}$, e a lâmina de água aplicada pela irrigação foi de $265 \mathrm{~mm}$ (1.727 mm, no total). As médias de temperaturas máxima e mínima foram de 32,2 e $13,1^{\circ} \mathrm{C}$, respectivamente.

Para avaliação da incidência da broca, em campo, amostrou-se inicialmente $1 \mathrm{~m}$ de fileira de cultivo por parcela, tendo-se separado folhas secas, colmos e ponteiro (folhas verdes, cartucho e palmito). 
Nos colmos amostrados, contou-se o número total de internódios e de orifícios provocados pela broca, por metro de cultivo. Esses dados foram utilizados para estimar o número total de internódios e de orifícios, em cada parcela. Em seguida, os colmos amostrados foram abertos longitudinalmente, para quantificação do número de internódios com danos característicos da podridão-vermelha. Foram determinados os seguintes parâmetros: número médio de orifícios, número médio de internódios com podridão-vermelha e percentagem de infestação (número de internódios infestados em relação ao número total de internódios). As avaliações foram realizadas em cinco épocas: abril (aos 208 dias após o corte da soqueira anterior, DAC), julho (291 DAC) e outubro (381 DAC) de 2010; e em março (165 DAC) e julho (285 DAC) de 2011.

Os colmos amostrados nas parcelas foram pesados após a despalha, com uso de balança tipo "célula de carga", graduada em 200 g. Em todas as avaliações, dez colmos foram subamostrados em cada parcela. Essas subamostras foram encaminhadas para $o$ Laboratório de Tecnologia da Associcana (Associação dos Produtores de Cana da Região de Jaú), para análises quanto aos valores de POL, fibra, açúcares redutores e açúcar total recuperável (ATR), conforme o Conselho dos Produtores de Cana-de-Açúcar, Açúcar e Álcool do Estado de São Paulo (2003). A produtividade de colmos, em tonelada de cana por hectare $(\mathrm{TCH})$, foi obtida por meio da relação proporcional com a área de cada parcela, exceto para a avaliação em outubro de 2010, quando o TCH foi calculado pela colheita de toda a parcela experimental. A tonelada de POL por hectare (TPH) foi obtida pelo produto entre a TCH e a percentagem de açúcar (PCC).

A atratividade e o consumo de fragmentos de colmo pela broca foram avaliados em laboratório $\left(\mathrm{T}=25 \pm 2^{\circ} \mathrm{C}, \mathrm{UR}=70 \pm 10 \%\right.$, e fotófase de 12 horas). Os insetos utilizados nesses testes foram obtidos de uma criação de $D$. saccharalis iniciada com pupas provenientes de criação massal da empresa DuPont (Estação Experimental de Paulínia, SP). As pupas foram acondicionadas em gaiolas de PVC, com $10 \mathrm{~cm}$ de diâmetro e $20 \mathrm{~cm}$ de altura, revestidas internamente com papel sulfite, para oviposição. As gaiolas foram tampadas com tecido tipo voile, na parte superior, e a parte inferior foi apoiada em placa de Petri revestida com papel-filtro. Após a emergência dos adultos, colocou-se uma porção de algodão umedecido em solução de mel a $10 \%$, em cada gaiola, com troca a cada dois dias (Parra, 2001).

Coletados diariamente do papel sulfite que continha a oviposição, os ovos foram esterilizados (Parra, 2001) e colados na parte superior do recipiente com a dieta artificial. As lagartas eclodidas permaneceram na dieta até a montagem dos bioensaios.

Para o teste com chance de escolha, seções do colmo de cana-de-açúcar sem a casca foram dispostas em círculo, de forma equidistante, em arenas de alumínio (50 $\mathrm{cm}$ de diâmetro por $5 \mathrm{~cm}$ de altura), forradas ao fundo com papel-filtro umedecido. Os colmos dispostos em cada arena provieram de todos os tratamentos avaliados em campo. Seções de $10 \mathrm{~g}$ dos colmos foram retiradas do sexto entrenó, contado a partir do solo. Nessas seções, foi aberta uma pequena galeria na parte inferior, para facilitar o consumo pela lagarta. Foram liberadas lagartas de 4ํ instar, na região central das arenas (dois indivíduos por tratamento). As arenas foram vedadas com filme de plástico transparente, com pequenos orifícios para entrada de ar. Foram realizadas cinco repetições, representadas por uma arena cada. Quantificou-se o número de lagartas nos tratamentos após 30 min e após 2, 6, 12, 24 e 48 horas da infestação. Após a última avaliação, as lagartas foram retiradas das arenas, e os tratamentos acondicionados em estufa a $60^{\circ} \mathrm{C}$, com circulação de ar, por 72 horas. O consumo foi determinado pela diferença de peso entre alíquotas de material vegetal seco, sem infestação, e de material seco obtido após a análise da infestação.

Para o teste sem chance de escolha, seções de colmo $(10 \mathrm{~g})$ dos mesmos tratamentos foram acondicionadas, isoladamente, no interior de recipientes de plástico $(50 \mathrm{~mL})$, revestidos com papel-filtro umedecido na base, e infestados com duas lagartas de 4o instar de D. saccharalis. Foram utilizadas dez repetições, em que cada recipiente representou uma repetição, em delineamento inteiramente casualizado. As avaliações de consumo seguiram o mesmo protocolo descrito para o teste com chance de escolha.

Todos os resultados foram submetidos à análise de variância pelo teste $\mathrm{F}$, a 5\% de probabilidade, tendo-se utilizado o programa Assistat.

Foram realizadas análises de regressão, com uso do programa SigmaPlot 11, para relacionar as doses de N às seguintes variáveis: número de orifícios e internódios afetados pela podridão-vermelha; percentagem de infestação; TCH; TPH; PCC; e ATR. 
Nos ensaios de laboratório, os resultados do número de lagartas foram transformados em $(\mathrm{x}+0,5)^{0,5}$ (Banzatto \& Kronka, 2006). Os demais resultados não foram transformados.

\section{Resultados e Discussão}

A análise de regressão mostrou resposta linear positiva entre as doses de $\mathrm{N}$ e a percentagem de internódios com sintomas de podridão-vermelha, na maioria das avaliações, com exceção da de março de 2011, quando a incidência da podridão foi próxima de zero (Tabela 1). Essa avaliação, provavelmente, foi prejudicada pela baixa infestação de D. saccharalis, com baixo número de orifícios causados pela broca. Na média geral das safras de 2010 e 2011, o incremento das doses de $\mathrm{N}$ aumentou a incidência da podridão-vermelha, com coeficientes de determinação de 0,46 e 0,31, respectivamente.

Embora a fertilização nitrogenada tenha aumentado a incidência da podridão-vermelha nos colmos, esta pôde ser classificada como de intensidade baixa a mediana, em todos os tratamentos. De acordo com Guagliumi (1972), a incidência da podridão é classificada de acordo com a seguinte escala: $0-5 \%$, baixa; 6-10\%, moderada; $11-15 \%$, mediana; $16-25 \%$, elevada; e, acima de $26 \%$, muito elevada.

Bortolli et al. (2005) verificaram que o desbalanceamento na nutrição nitrogenada do sorgo possivelmente aumentou a incidência da podridão-vermelha, em que doses intermediárias de $\mathrm{N}$ (10 e $20 \mathrm{~g}$ de $\mathrm{N}$ por $10 \mathrm{~L}$ de solo) proporcionaram médias de infestação menores $(57,41$ e $49,70 \%$, respectivamente) do que doses baixas ( $5 \mathrm{~g})$ e altas ( $40 \mathrm{~g})$ de $\mathrm{N}$ (infestações de 70,53 e 65,47\%, respectivamente), em experimento em casa de vegetação.

Apesar do aumento da incidência da podridão-vermelha, a fertilização nitrogenada foi efetiva no aumento da produtividade $(\mathrm{TCH})$, em todas as avaliações realizadas (Tabela 2). A TCH aumentou de forma linear com as doses de $\mathrm{N}$, com coeficientes de determinação de 0,85 e 0,73 , respectivamente para

Tabela 1. Percentagem de internódios com sintomas de podridão-vermelha, em consequência das doses de $\mathrm{N}$ aplicadas à cana de açúcar fertirrigada por gotejamento, nas avaliações de abril, julho e outubro de 2010, e de março e julho de $2011^{(1)}$.

\begin{tabular}{|c|c|c|c|c|c|c|c|}
\hline \multirow{2}{*}{$\begin{array}{l}\text { Doses de N } \\
\left(\mathrm{kg} \mathrm{ha}^{-1}\right)\end{array}$} & \multicolumn{3}{|c|}{ Infestação dos internódios (\%) } & \multirow[t]{2}{*}{ Média } & \multicolumn{2}{|c|}{ Infestação dos internódios (\%) } & \multirow[t]{2}{*}{ Média } \\
\hline & $4 / 2010$ & $7 / 2010$ & $10 / 2010$ & & $3 / 2011$ & $7 / 2011$ & \\
\hline 0 & 4,99 & 4,94 & 5,22 & 5,05 & 0,24 & 1,93 & 1,08 \\
\hline 50 & 5,51 & 10,93 & 5,94 & 7,46 & 0,31 & 1,60 & 0,96 \\
\hline 100 & 7,62 & 12,04 & 9,06 & 9,57 & 0,00 & 2,87 & 1,44 \\
\hline 150 & 8,11 & 11,41 & 7,84 & 9,12 & 0,00 & 3,05 & 1,53 \\
\hline 200 & 12,50 & 13,74 & 9,78 & 12,01 & 1,90 & 3,32 & 2,61 \\
\hline $\mathrm{CV}(\%)$ & 44,86 & 36,71 & 36,86 & 26,77 & 216,04 & 48,64 & 50,40 \\
\hline F regressão linear & $10,29 *$ & $13,74^{*}$ & $6,26^{*}$ & $22,10 *$ & $3,20^{\mathrm{ns}}$ & $6,35^{*}$ & $10,58 *$ \\
\hline $\mathrm{R}^{2}$ & $0,38^{*}$ & $0,22 *$ & $0,24 *$ & $0,46^{*}$ & $0,13^{\mathrm{ns}}$ & $0,22 *$ & $0,31^{*}$ \\
\hline
\end{tabular}

(1)Avaliações de: abril de 2010, aos 208 dias após o corte da soqueira (DAC); julho de 2010, aos 291 DAC; outubro de 2010, 381 DAC; março de 2011, 165 DAC; e julho de 2011, 285 DAC. ns Não significativo. *Significativo a 5\% de probabilidade, pelo teste F.

Tabela 2. Produtividade de colmos (TCH) e de açúcar (TPH), em consequência das doses de N aplicadas à cana-de-açúcar fertirrigada por gotejamento, nas avaliações de abril, julho e outubro de 2010, e de março e julho de $2011^{(1)}$.

\begin{tabular}{|c|c|c|c|c|c|c|c|c|c|c|c|c|c|c|}
\hline \multirow{2}{*}{$\begin{array}{l}\text { Doses de N } \\
\left(\mathrm{kg} \mathrm{ha}^{-1}\right)\end{array}$} & \multicolumn{3}{|c|}{$\mathrm{TCH}\left(\mathrm{Mg} \mathrm{ha}^{-1}\right)$} & \multirow[t]{2}{*}{ Média } & \multicolumn{2}{|c|}{ TCH $\left(\mathrm{Mg} \mathrm{ha}^{-1}\right)$} & \multirow[t]{2}{*}{ Média } & \multicolumn{3}{|c|}{$\mathrm{TPH}\left(\mathrm{Mg} \mathrm{ha}^{-1}\right)$} & \multirow[t]{2}{*}{ Média } & \multicolumn{2}{|c|}{$\mathrm{TPH}\left(\mathrm{Mg} \mathrm{ha}^{-1}\right)$} & \multirow[t]{2}{*}{ Média } \\
\hline & $4 / 2010$ & $7 / 2010$ & $10 / 2010$ & & $3 / 2011$ & $7 / 2011$ & & $4 / 2010$ & $7 / 2010$ & $10 / 2010$ & & $3 / 2011$ & $7 / 2011$ & \\
\hline 0 & 31,11 & 36,11 & 59,21 & 42,14 & 22,85 & 42,23 & 32,54 & 3,8 & 5,80 & 10,08 & 6,57 & 1,98 & 6,70 & 4,34 \\
\hline 50 & 38,06 & 52,78 & 75,35 & 55,40 & 22,48 & 42,78 & 32,63 & 4,3 & 8,04 & 12,80 & 8,38 & 2,09 & 6,78 & 4,44 \\
\hline 100 & 54,17 & 83,90 & 90,74 & 76,27 & 28,74 & 59,17 & 43,96 & 5,9 & 12,73 & 15,91 & 11,52 & 2,59 & 9,38 & 5,98 \\
\hline 150 & 68,06 & 85,15 & 109,35 & 87,52 & 26,74 & 85,01 & 55,87 & 7,5 & 12,97 & 18,39 & 12,95 & 2,35 & 13,43 & 7,89 \\
\hline 200 & 74,17 & 91,54 & 120,50 & 95,40 & 45,27 & 84,82 & 65,04 & 7,9 & 13,46 & 18,91 & 13,42 & 3,89 & 12,95 & 8,42 \\
\hline CV (\%) & 26,97 & 17,64 & 6,76 & 11,13 & 19,25 & 15,44 & 13,32 & 25,20 & 11,27 & 6,85 & 7,86 & 22,35 & 16,32 & 13,71 \\
\hline F reg. linear & $26,29 *$ & $53,99 *$ & $259,07 *$ & $121,96^{*}$ & $30,47^{*}$ & $69,07 *$ & $82,96 *$ & $23,43^{*}$ & $115,04^{*}$ & $199,11 *$ & $193,86^{*}$ & $20,02 *$ & $56,82 *$ & $74,31 *$ \\
\hline $\mathrm{R}^{2}$ & $0,64^{*}$ & $0,68 *$ & $0,92 *$ & $0,85^{*}$ & $0,51 *$ & $0,65^{*}$ & $0,73 *$ & $0,64 *$ & $0,71 *$ & $0,87^{*}$ & $0,86^{*}$ & $0,44^{*}$ & $0,62^{*}$ & $0,70^{*}$ \\
\hline
\end{tabular}

(1)Avaliações de: abril de 2010, aos 208 dias após o corte da soqueira (DAC); julho de 2010, aos 291 DAC; outubro de 2010, 381 DAC; março de 2011, 165 DAC; e julho de 2011,

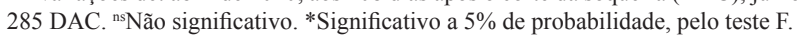


as safras de 2010 e 2011. Como a regressão entre essas variáveis foi linear, a dose mais elevada de $\mathrm{N}$ $\left(200 \mathrm{~kg} \mathrm{ha}^{-1}\right)$, em geral, propiciou a maior produtividade de colmos. Resultados semelhantes foram observados por Moura et al. (2005), que relataram comportamento linear positivo entre $\mathrm{TCH}$ e doses de $\mathrm{N}$ e $\mathrm{K}$, em cobertura tanto em cana-de-açúcar irrigada como em sequeiro.

A adubação nitrogenada também aumentou a produtividade de açúcar (POL), com coeficientes de determinação de 0,86 e 0,70 , respectivamente, para as safras de 2010 e 2011 (Tabela 2). Esse resultado provavelmente esteve relacionado ao aumento significativo da produtividade de colmos. Embora houvesse a expectativa de que infestações mais elevadas do complexo broca-podridão pudessem afetar o peso e o teor de açúcar dos colmos e prejudicar a produtividade da cultura, o incremento de $\mathrm{TCH}$ proporcionado pela adubação foi muito maior do que os possíveis danos da infestação, o que justificou o uso mesmo das maiores doses de $\mathrm{N}$.

$\mathrm{O}$ número de orifícios correlacionou-se positivamente ao número de internódios afetados pela podridão-vermelha $(p<0,05)$, em todas as épocas de avaliação (Tabela 3). Os meses de julho e outubro de 2010 e julho de 2011 mostraram os maiores coeficientes de correlação (acima de 0,90) entre essas variáveis. O coeficiente angular da regressão foi de 0,4 , ou seja, em média, a cada 2,5 orifícios encontrados verificou-se 1,0 internódio com podridão-vermelha (Tabela 3). Para o cálculo da razão entre os parâmetros, foi excluído o mês de março de 2011, em razão da baixa incidência de broca observada nessa avaliação.

$\mathrm{O}$ número de internódios com sintomas de podridão-vermelha correlacionou-se negativamente $(\mathrm{p}<0,05)$ à percentagem de açúcar no colmo (PCC), nos meses de abril, julho e outubro de 2010, com coeficiente de correlação de $0,65,0,71$ e 0,60, respectivamente (Tabela 3). Em março e julho de 2011, não houve correlação significativa entre as variáveis. Possivelmente, a baixa infestação das parcelas, em março de 2011, comprometeu a verificação de interação entre os fatores.

Silva \& Campos (1975) constataram que a POL diminuiu significativamente com o aumento da incidência do complexo broca-podridão, em diferentes variedades de cana-de-açúcar. Os autores concluíram que a broca pode ser um fator altamente prejudicial à produtividade de açúcar. Além disso, a presença dos fungos causadores da podridão-vermelha, nas galerias feitas pela broca, pode contaminar o caldo e resultar na competição com as leveduras, durante o processo de fermentação alcoólica, com subsequente perda na produção de açúcar e álcool (Botelho, 1992).

O número de lagartas em cada fragmento de colmo, no ensaio da atratividade com chance de escolha, não se correlacionou às doses de $\mathrm{N}$ (Tabela 4), em nenhuma das épocas de avaliação e nem na média geral das observações. Portanto, a fertilização nitrogenada não aumentou a atratividade dos fragmentos à broca. No entanto, as doses de $\mathrm{N}$ aumentaram o consumo dos fragmentos pelo inseto. A relação entre essas variáveis foi significativa e apresentou coeficiente de determinação de 0,20 , para o teste com chance de escolha, e de 0,44 , para o teste sem chance de escolha. Portanto, o consumo de fragmentos de colmos por lagartas de quarto instar de $D$. saccharalis aumentou de forma linear positiva com as doses de N, nos dois testes em laboratório.

Esses resultados sugerem que a adubação nitrogenada aumenta a palatabilidade dos fragmentos de colmo às lagartas.

Tabela 3. Relação entre o número de internódios com sintomas de podridão vermelha com o número de orifícios e a percentagem de açúcar (PCC) nos colmos, nas cinco épocas de avaliação, nas safras de 2010 e 2011.

\begin{tabular}{|c|c|c|c|c|}
\hline \multirow[t]{2}{*}{ Avaliação } & \multicolumn{2}{|c|}{ Número de orifícios } & \multicolumn{2}{|c|}{ Percentagem de açúcar } \\
\hline & Equação & $\mathrm{R}^{2}$ & Equação & $\mathrm{R}^{2}$ \\
\hline Abril de 2010 & $y=0,2245 x+6,0855$ & $0,85^{*}$ & $y=-0,0528 x+12,321$ & $0,65^{*}$ \\
\hline Julho de 2010 & $y=0,4729 x+0,674$ & $0,97 *$ & $y=-0,0389 x+16,588$ & $0,71 *$ \\
\hline Outubro de 2010 & $y=0,4318 x+1,6253$ & $0,93 *$ & $y=-0,0478 x+18,116$ & $0,60 *$ \\
\hline Março de 2011 & $y=0,0235 x-0,2045$ & $0,78^{*}$ & $y=-0,0414 x-8,8735$ & $0,13^{\text {ns }}$ \\
\hline Julho de 2011 & $y=0,4694 x-0,4335$ & $0,96^{*}$ & $\mathrm{y}=-0,0331 \mathrm{x}-15,971$ & $0,35^{\text {ns }}$ \\
\hline Cinco épocas & $y=0,386 x+1,5224$ & $0,92 *$ & - & - \\
\hline
\end{tabular}

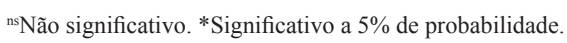


Tabela 4. Média do número de lagartas de Diatraea saccharalis atraídas por fragmentos de colmo de cana-de-açúcar, no ensaio com chance de escolha, e do consumo dos fragmentos nos ensaios com ou sem chance de escolha ${ }^{(1)}$.

\begin{tabular}{|c|c|c|c|c|c|c|c|c|c|}
\hline \multirow{2}{*}{$\begin{array}{l}\text { Doses de N } \\
\left(\mathrm{kg} \mathrm{ha}^{-1}\right)\end{array}$} & \multicolumn{6}{|c|}{ Número de lagartas } & \multirow[t]{2}{*}{ Média } & \multicolumn{2}{|c|}{ Consumo $(\mathrm{g})$} \\
\hline & $30 \mathrm{~min}$ & $2 \mathrm{~h}$ & $6 \mathrm{~h}$ & $12 \mathrm{~h}$ & $24 \mathrm{~h}$ & $48 \mathrm{~h}$ & & Com chance de escolha & Sem chance de escolha \\
\hline 0 & 0,3 & 1,0 & 1,0 & 1,1 & 1,0 & 1,1 & 0,9 & 0,11 & 0,22 \\
\hline 50 & 0,5 & 1,0 & 1,0 & 1,1 & 0,9 & 1,4 & 1,0 & 0,12 & 0,24 \\
\hline 100 & 0,6 & 1,1 & 1,1 & 1,1 & 1,1 & 1,6 & 1,1 & 0,21 & 0,27 \\
\hline 150 & 0,6 & 1,1 & 1,2 & 1,2 & 1,2 & 1,1 & 1,1 & 0,31 & 0,29 \\
\hline 200 & 1,0 & 1,6 & 1,7 & 1,6 & 1,8 & 1,8 & 1,6 & 0,27 & 0,49 \\
\hline Média & 0,6 & 1,2 & 1,2 & 1,2 & 1,2 & 1,4 & 1,1 & 0,21 & 0,30 \\
\hline$\overline{C V}(\%)$ & 23,74 & 19,60 & 21,37 & 20,70 & 21,12 & 20,99 & 15,01 & 73,40 & 29,97 \\
\hline F regressão linear & $4,85^{\mathrm{ns}}$ & $1,82^{\text {ns }}$ & $2,12^{\mathrm{ns}}$ & $1,09^{\mathrm{ns}}$ & $3,22^{\text {ns }}$ & $0,74^{\mathrm{ns}}$ & $3,83^{\text {ns }}$ & $5,42 *$ & $21,88^{*}$ \\
\hline $\mathrm{R}^{2}$ & 0,188 & 0,090 & 0,111 & 0,060 & 0,157 & 0,053 & 0,123 & 0,2036 & 0,4391 \\
\hline
\end{tabular}

${ }^{(1)}$ Os dados foram transformados em $(\mathrm{x}+0,5)^{0,5}$. ns Não significativo. *Significativo a $5 \%$ de probabilidade, pelo teste $\mathrm{F}$.

\section{Conclusões}

1. A fertirrigação nitrogenada aumenta a incidência de Diatraea saccharalis e a podridão-vermelha em cana-de-açucar fertirrigada.

2. O número de orifícios causados pela lagarta correlaciona-se à ocorrência de podridão-vermelha.

3. A percentagem de açúcar diminui com o aumento do número de internódios afetados pela podridão-vermelha; porém, a produtividade de colmos e de açúcar aumenta consideravelmente com a adubação nitrogenada, o que justifica o uso mesmo das maiores doses de $\mathrm{N}$ (150 e $\left.200 \mathrm{~kg} \mathrm{ha}^{-1}\right)$.

4. A adubação nitrogenada não afeta a atratividade dos fragmentos de colmo a $D$. saccharalis, mas aumenta seu consumo pela lagarta.

\section{Referências}

ANDRADE JÚNIOR, A.S. de; BASTOS, E.A.; RIBEIRO, V.Q.; DUARTE, J.A.L.; BRAGA, D.L.; NOLETO, D.H. Níveis de água, nitrogênio e potássio por gotejamento subsuperficial em cana-de-açúcar. Pesquisa Agropecuária Brasileira, v.47, p.76-84, 2012. DOI: 10.1590/S0100-204X2012000100011.

BANZATTO, D.A.; KRONKA, S. do N. Experimentação agrícola. 4.ed. Jaboticabal: Funep, 2006. 237p.

BORTOLLI, S.A. de; DÓRIA, H.O.S.; ALBERGARIA, N.M.M.S.; BOTTI, M.V. Aspectos biológicos e danos de Diatraea saccharalis (Fabr., 1794) (Lepidoptera: Pyralidae) em sorgo cultivado sob diferentes doses de nitrogênio e potássio. Ciência e Agrotecnolgia, v.29, p.267-273, 2005. DOI: 10.1590/ S1413-70542005000200001.

BOTELHO, P.S.M. Quinze anos de controle biológico da Diatraea saccharalis utilizando parasitóides. Pesquisa Agropecuária Brasileira, v.27, p.255-262, 1992.
CARVALHO, F.T. de; QUEIROZ, J.R.G.; TOLEDO, R.E.B. de. Eficácia do herbicida amicarbazone no controle de cordas-de-viola na cultura da cana-de-açúcar (Saccharum spp.). Revista Brasileira de Herbicidas, v.10, p.183-189, 2011.

CONSELHO DOS PRODUTORES DE CANA-DE-AÇÚCAR, AÇÚCAR E ÁLCOOL DO ESTADO DE SÃO PAULO. Manual de instruções. 4.ed. Piracicaba: Consecana, 2003. 115p.

DIAS, N. da S.; BROGLIO-MICHELETTI, S.M.F.; FARIAS, N.R. de M.; COSTA, S.S. da; SANTOS, J.M. dos; LOPES, D.O.P.; COSTA, V.A. Ocorrência de Telenomus alecto Crawford, 1914 (Hymenoptera: Scelionidae) em ovos de Diatraea spp. (Lepidoptera: Crambidae) em cana-de-açúcar no Estado de Alagoas, Brasil. Idesia, v.29, p.95-97, 2011. DOI: 10.4067/S0718-34292011000300014.

DINARDO-MIRANDA, L.L. Cigarrinha das raízes em cana-de-açúcar. Campinas: Instituto Agronômico, 2003. 72p.

DINARDO-MIRANDA, L.L. Pragas. In: DINARDO-MIRANDA, L.L.; VASCONCELOS, A.C.M. de; LANDELL, M.G. de A. (Ed.). Cana-de-açúcar. Campinas: Instituto Agronômico, 2008. p.349-404.

DINARDO-MIRANDA, L.L.; ANJOS, I.A. dos; COSTA, V.P. da; FRACASSO, J.V. Resistance of sugarcane cultivars to Diatraea saccharalis. Pesquisa Agropecuária Brasileira, v.47, p.1-7, 2012. DOI: 10.1590/S0100-204X2012000100001.

DINARDO-MIRANDA, L.L.; FRACASSO, J.V.; PERECIN, D. Variabilidade espacial de populações de Diatraea saccharalis em canaviais e sugestão de métodos de amostragem. Bragantia, v.70, p.577-585, 2011. DOI: /10.1590/S0006-87052011005000008.

FARONI, C.E.; TRIVELIN, P.C.O.; SILVA, P.H. da; BOLOGNA, I.R.; VITTI, A.C.; FRANCO, H.C.J. Marcação de fitomassa de cana-de-açúcar com aplicação de solução de uréia marcada com ${ }^{15}$ N. Pesquisa Agropecuária Brasileira, v.42, p.851-857, 2007. DOI: 10.1590/S0100-204X2007000600012.

GUAGLIUMI, P. Pragas da cana-de-açúcar: Nordeste do Brasil. Rio de Janeiro: IAA, 1972. 622p. (IAA. Coleção canavieira, 10).

MOURA, M.V.P. da S.; FARIAS, C.H. deA.;AZEVEDO, C.A.V. de; DANTAS NETO, J.; AZEVEDO, H.M. de; PORDEUS, R.V. Doses de adubação nitrogenada e potássica na cultura da cana-de-açúcar, 
primeira soca, com e sem irrigação. Ciência e Agrotecnologia, v.29, p.753-760, 2005. DOI: 10.1590/S1413-70542005000400006.

OLIVEIRA, E.C.A. de; FREIRE, F.J.; OLIVEIRA, A.C. de; SIMÕES NETO, D.E.; ROCHA, A.T. da; CARVALHO, L.A. de. Produtividade, eficiência de uso da água e qualidade tecnológica de cana-de-açúcar submetida a diferentes regimes hídricos. Pesquisa Agropecuária Brasileira, v.46, p.617-625, 2011. DOI: 10.1590/ S0100-204X2011000600007.

OLIVEIRA, F.G. de L. Ocorrência de Diatraea saccharalis (Lepidoptera: Pyralidae) em plantações de cana-de-açúcar (Magnoliophyta: Poaceae) em diferentes localidades no município de Paraty - RJ. Revista Controle Biológico, v.1, p.6-10, 2009.

PARRA, J.R.P. Técnicas de criação de insetos para programas de controle biológico. 6.ed. rev. ampl. Piracicaba: ESALQ/ FEALQ, 2001. 134p.

SANTOS, H.G. dos; JACOMINE, P.K.T.; ANJOS, L.H.C. dos; OLIVEIRA, V.A. de; OLIVEIRA, J.B. de; COELHO, M.R.; LUMBRERAS, J.F.; CUNHA, T.J.F. (Ed.). Sistema brasileiro de classificação de solos. 2.ed. Rio de janeiro: Embrapa Solos, 2006. $306 p$.
SILVA, G.M. de A.; CAMPOS, R.B. Influência do ataque do complexo broca-podridões na composição da cana-de-açúcar. In: SEMINÁRIO COPERSUCAR DA AGROINDÚSTRIA AÇUCAREIRA, 3., 1975, Águas de Lindóia. Anais. Águas de Lindóia: Copersucar, 1975. p.233-240.

TANEJA, S.L.; DHINDWAL, A.S. Bollworm incidence as affected by sowing date, nitrogen application and plant population in upland cotton. Indian Journal of Plant Protection, v.10, p.1-6, 1982.

VALE, D.W. do; PRADO, R. de M.; AVALHÃES, C.C.; HOJO, R.H. Omissão de macronutrientes na nutrição e no crescimento da cana-de-açúcar cultivado em solução nutritiva. Revista Brasileira de Ciências Agrárias, v.6, p.189-196, 2011. DOI: 10.5039/agraria. v6i2a550.

WIEDENFELD, B.; ENCISO, J. Sugarcane responses to irrigation and nitrogen in semiarid South Texas. Agronomy Journal, v.100, p.665-671, 2008. DOI: 10.2134/agronj2007.0286.

ZING, Y.L.; GONG, P.Y.; JIANG, L.R. Effects of nitrogen fertilizer application of the cotton plant and the bollworm. Acta Entomologica Sinica, v.25, p.16-23, 1982.

Recebido em 17 de julho de 2012 e aprovado em 1 de abril de 2013 